\title{
Dilemas Éticos como Proposta Metodológica para Abordar Temas Transversais
}

\author{
Dilemas Éticos como Propuesta Metodológica para Abordar Cuestiones \\ Transversales
}

\author{
Me. Sansao Albino Timbane'; Dra. Margarete Axt² \\ ${ }^{1}$ sansaot@gmail.com, Universidade Federal do Rio Grande do Sul; ${ }^{2}$ maaxt03@gmail.com, \\ Universidade Federal do Rio Grande do Sul.
}

\begin{abstract}
Resumo
O presente estudo realça como o investimento em dilemas éticos pode contribuir como disparador da aprendizagem em Ambientes Virtuais voltados a aprendizagem, mais do que ao ensino. Foram realizados encontros presenciais, em sala de aula, e a distância, no espaço online (Forchat). Os alunos participaram proativamente das discussões com liberdade de decisão quanto à assunção de papeis e à proposição de temáticas de seu interesse ligadas aos tópicos em estudo, ora assumindo a função de moderador, ora à de contribuinte, sem interferência expressa da professora.

A problematização da realidade pela via de dilemas éticos apresentou como efeito relevante o engajamento proativo nas discussões dos assuntos propostos e gerados a posteriori, com ganhanhos para a construção conceitual e os posicionamentos metodológicos na pesquisa e na docência. Instigados pelo desafio de temas transversais discutiram, no ambiente virtual de aprendizagem, temáticas relacionadas com: prática docente, aprendizagem, formação profissional, avaliação, relação teoria-prática, atualizando debates e reflexões em torno de dilemas éticos, dando corpo a um texto coletivo que ao mesmo tempo respeitou a heterogeneidade das contribuições individuais e dos sentidos produzidos.
\end{abstract}

Palavras-Chave: Dilema ético, Educação, Cultura, Tema transversal.

\section{Resumen}

Este estudio pone de relieve cómo la inversión en dilemas éticos puede contribuir a desencadenar el aprendizaje en entornos virtuales de aprendizaje dirigido en lugar de enseñar. Se celebraron reuniones de la cara en el aula, y la distancia, en el espacio online (Forchat). Los estudiantes participaron activamente en las discusiones con la libertad de decisión sobre la asunción de roles y la propuesta temática de interés vinculados a los temas objeto de estudio, tomando a veces de moderador, a veces para el contribuyente, sin interferencia expresa por parte del maestro. El cuestionamiento de la realidad a través de los dilemas éticos que se presentan como efecto material participación activa en las discusiones de los temas propuestos y genera a posteriori, con ganhanhos para la construcción de las posiciones conceptuales y metodológicos en la investigación y la enseñanza. Instigado por el desafío de temas transversales tratados en el entorno virtual de aprendizaje, las cuestiones relacionadas con: la práctica, el aprendizaje, la formación, la evaluación, la relación entre la teoría y la práctica, la actualización de debate y reflexión en torno a los dilemas éticos enseñanza, que incorpora un texto colectivo al mismo tiempo, respetar la heterogeneidad de las contribuciones individuales y los significados producidos.

Palabras-Clave: Dilema ético, Educación, Cultura, Tema transversal.

\section{Introdução}

Os desafios da vida, os problemas que nos são apresentados no nosso cotidiano e, consequentemente à escola, não são sigulares do ponto de vista epistemológico, mas abrangem diversas áreas do ser e do conhecimento, são de índole interdisciplinar, dai que, 
abordar estes problemas na escola é vivenciá-los; implica um pensar e fazer transdisciplinar. O mundo vê-se confrotado por situações controversas, que para seu entendimento e tratamento não deve passar somente por uma formação disciplinar rígida que é a base da actual formação e ensino.

Discutir temas transversais é um exercício de pensar e agir, pensar globalmente (dialogar com o mundo) e agir localmente (entender e resolver o problema concreto, no micro-mundo). Aprendemos, reconhecemos, interpretamos o mundo através da leitura e escuta integrada dos signos, mobilizando as sensações, afecções e percepções, a atmosfera circunstancial (tempo e micro-espaço social) e seus ruídos. Ai, aprendizagem resulta do estabelecimento de novas conexões, o que inclui, novas conexões neurais no cérebro humano. Neste processo, o cérebro do aprendente recria as memórias e estabelece novas hierarquias com objeto de aprendizagem, realizando simultaneamente e de forma integrada, cálculos, interpretações de ordem histórico, biológico, geográfico, químico, linguístico-semântico.

Se bem que, como refere Morin (2002), a disciplina é uma categoria organizadora no seio do conhecimento científico, um domínio autônomo, com técnicas, linguagem e eventualmente com teorias que lhe são próprias. Tal organização intituiu-se no século XIX e desenvolveu-se no século XX com o progresso do método científico, propiciando uma divisão e especialização do trabalho dentro das suas fronteiras. Portanto, a disciplina é um todo organizado recortado do caos (sociedade), que renuncia ao infinito para ganhar uma referência capaz de atualizar o virtual por meio de funções (DELEUZE; GUATTARI, 2007). Neste sentido, Morin parece concordar com importância de algumas propriedades do caos em Deleuze e Gattari, ao afirmar que: "A disciplina releva, então, não só de um conhecimento e de uma reflexão interna sobre si mesma, mas também de um conhecimento externo. Não é suficiente pois estar no interior de uma disciplina para conhecer todos os problemas referentes a esta." (MORIN, 2002, p. 113). Deleuze e Guattari (2007, p.161) enfatizam que as bifurcações, as desacelerações e acelerações produzem buracos, cortes e ropturas, que remetem a outras variáveis, outras relações e outras referências.

Por exemplo, como discuitir o preço da passagem de "chapa" (nome usado para o transportes Semi-colectivo de passageiros em Moçambique, equivalente a lotação no Brasil.) ou "machimbombo" (designação para autocarros do Sistema de Transportes Público em Moçambique, equivalente a Ónibus no Brasil.) ou barco de Matola-Rio à Baixa da Cidade de Maputo (Praça dos Trabalhadores), sem as contribuições das disciplinas Matemática (cálculos, estatísticas), Geografia (localização, mobilidade urbana), História (topominia, património cultural) Química (combustíveis, poluição), Informática (produção de gráficos, 
apresentação, internet), Desenho (cartazes)? As pesquisas da Paleontologia, Astrofísica e Cosmologia são exemplos dessa mudança paradigmática e eventualmente sintagmática realizada ha milhões de anos e que hoje nos preocupamos com a conceitualização e utilização prática. Agregam-se ainda, as Ciências Ecológicas, a Biologia Molecular, Informática na Educação, entre outros.

Mesmo reconhecendo que, qualquer tentativa de definição rígida do conceito leva ao seu fechamento, Alvarenga et al. (2011, p. 49-50) apresenta-nos o quadro conceitual a seguir, que nos permite uma abstração inicial sobre a inter e transdisciplinaridade.

1. Disciplina. Conjunto específico de conhecimentos que tem suas características próprias no plano do ensino, da formação, dos mecanismos, dos métodos e das matérias.

2. Multidisciplina. Justaposição de disciplinas diversas, às vezes sem relação aparente entre si, como a música, a matemática, a história.

3. Pluridisciplina. Justaposição de disciplinas mais ou menos vizinhas em áreas do conhecimento, como, no campo científico, a matemática e a física, ou, em áreas das letras, o francês, o latim e o grego.

4. Interdisciplina. Interação existente entre duas ou mais disciplinas, podendo ir da simples comunicação de ideias até a integração mutual dos conceitos diretores, da epistemologia, da terminologia, dos procedimentos, dos dados e da organização da pesquisa e do ensino a elas relacionados. Um grupo interdisciplinar se compõe de pessoas que receberam uma formação em diferentes áreas dos conhecimentos (disciplinas), tendo, cada uma, conceitos, métodos, dados e termos próprios.

5. Transdisciplina. Colocar em ação uma axiomática comum em um conjunto de disciplinas, como, por exemplo, a antropologia, considerada "a ciência do homem e de suas obras", conforme a definição de Linton. (ALVARENGA et al, 2011, p. 49$50)$.

Ao abordar os temas tranversais em contexto educacional, a transdisciplinaridade oportuna o exercício de construção coletiva, que implica no diálogo e na escuta integral do outro, principalmente o outro ser humano como centro de valores (AXT, 2014). Centro de valores que valorizam e precisam ser valorizados e, que lhe conferem o poder de tomada de decisão. Valores que compõem a subjetividade individual no seu micro e macromundo. Valores morais, éticos; valores assimilados e assumidos; refletidos e refratados; a consciência e a sua capacidade de aprender em constante negociação (transmutação).

Um processo de ensino-aprendizagem, que considera o ser humano como centro de valores, agrega moral e ética que o regula e o previne dos seus efeitos indesejáveis, é portanto, uma decisão ética e estética.

\subsection{Contextualização}


O presente texto trata das relações entre inter/trans/disciplinar e transversalidade temática no âmbito do ensino superior com vista a formação docente, caracterizando uma abordagem metodológica de escuta dialógica e de respeito à produção de sentidos que se dá no determinado contexto problemático, oriunda de resultados de pesquisa relacionados ao Programa Interinstitucional Comunidades de Aprendizagem, Estética do Virtual e Autoria Coletiva (PROVIA), vinculado ao Laboratório de Estudos em Linguagem, Interação e Cognição (LELIC), da Universidaede Federal do Rio Grande do Sul (UFRGS). Este trabalho foi financiado pelo Conselho Nacional de Desenvolvimento Científico e Tecnológico (CNPq), processo MCT-MZ nº 47/2012-GD.

\subsection{Objetivos}

É propósito aqui criar algumas possibilidades de problematização de dilemas éticos que se constituam como dinamizadores principais de estratégias de aprendizagem relacionadas a valores axiológicos, com destaque para o cuidado ético de respeito na relação eu-outro, no coletivo e no contexto escolar caraterizado pela aprendizagem cognitiva e técnica.

\section{Do pensar e agir inter-transdisciplinar}

Embora a interdisciplinaridade não seja um conceito novo, como refere Pena-Vega (2011), Alvarenga (2011), Leis (2011), há um urgente emergir dum pensar e agir interdisciplinar e transdisciplinar, do ponto de vista epistemelógico e metodológico, num ambiente de crise da áreas disciplinar específicas em consequência da complexa evolução dos conhecimentos do mundo nos últimos 30 anos.

A natureza do ser humano é heterogénica na sua subjetividade, no seu processo de afirmação e no seu atuar social. Enquanto no mundo, ele procura selecionar encontros que lhe vão potenciar a solucionar os problemas com os quais se depara. A aprendizagem se dará no encontro dos conteúdos do problema real ou criado com os sentidos produzidos nos processos de reprodução e invenção de soluções para tais problemas. Segundo Deleuze \& Guattari (2007), as realidades são formadas por multiplicidades, que abrem novos horizontes, que propiciam agenciamentos coletivos e a atualização do virtual. No caso do conhecimento, e com o advento das Novas Tecnologias de Informação e Comunicação (incluindo a Internet), há muitas informações e conhecimentos sendo produzidos e disseminados rizomaticamente. Estes estão ao alcance do sujeito por meio do exercício estético do pensamento e interpretação 
das sensações, percepções e afecções. A potência da vida está na consubstancialidade da liberdade emanente do pensar.

Para Parente (1999) e Deleuze \& Guattari (2007), pensar é pensar em rede. A rede assume a dimensão de lugar de confluências, um lugar de co-habitação do real e do virtual, lugar de trocas constantes de identidades, afetando e sendo afetado pelos seus efeitos e atores, implicando-se nela e por ela, participando, colaborando e interagindo com outros pares na rede.

O sujeito se forma na rede, pelas redes, alterando constantemente os seus estados. O sujeito não possui uma essência ou natureza fixa; ele é um lugar de confrontos subjectivos. Os indivíduos e as colectividades se constituem como sujeitos por meio de subjetivação. Eles só valem na medida em que resistem e escapam tanto aos poderes quanto aos saberes disciplinares constituídos. Os poderes e saberes suscitam resistências e conduzem à autoreferência, auto-afecção. A subjetividade é constituída na interação do sujeito com a rede, pois nela, ele se constitui através do olhar do outro sobre si, deixando-se afectar e estabelecendo novas conexões e relações. Estas relações são da ordem do intensivo, além do sujeito, impregnadas de interdisciplinaridade e transdisciplinaridade. A produção do novo está ligado ao que vem de fora, aos agenciamentos que o sujeito experimenta ao se deixar afectar pelas contribuições alheias.

A disciplina é reducionista, fechada. Esta limitação pode ser rompida pelo diálogo entre as disciplinas, embora num sóbrio desafio de complementaridade da interdisciplinaridade e transdisciplinaridade. A interdisciplinaridade coopera com as disciplinas e, a transdisciplinaridade opera no limite dessa cooperação, organizando e articulando-a. É uma relação de coexistência, de fucionalismo e não de hierarquia estrutural. No tratamento de temas transversais, a interdisciplinaridade presta-se ao papel de dialogar com as disciplinas fornecendo os subsídios ás temáticas especiais, enquanto a transdisciplinaridade (transversalidade) vincula a abordagem dessas temáticas à projeto social, à prática, à vida do aluno.

Os temas transversais devem ser reais e ter impacto na sociedade, devem ser urgentes e possíveis de ser abordados na escola, no contexto sócio-político-económico-culturaltecnológico. Os temas transversais exploram diferentes dimensões do conhecimento humano. Suscitam do aluno a sua vivência na escola, a partir das suas experiências nos mídias, na família, amigos, etc. Os temas transversais vinculam uma aprendizagem da realidade sustentada na realidade atual ou virtual, reintegrando os conhecimentos teóricos, técnicos, científicos que ficaram de fora pelo método de organização disciplinar. Considerando a 
complexidade dos problemas do mundo, a sua solução deve tomar em consideração epistemologias, metodologias, experiências pessoais e os diálogos disciplinares resultantes do problema específico.

Assim, entende-se a transdisciplinaridade como maleável, atravessando as disciplinas clássicas. Sua conceituação entendida na concretude da praxis pedagógica, como exercício meta-interdisciplinar (cultura de transdisciplinaridade).

\subsection{Os temas transversais na escola}

É frequente associar a abordagem de temas transversais às questões sociais que emergem dum temática em estudo, cujo seu estudo se revela urgente e significativo no contexto socio-cultural do grupo e da escola. Tal abordagem se justifica na responsabilidade social da escola. A escola está inserida numa sociedade e tudo que nela ocorre, a ela diz respeito, a ela impacta; seus atores são sujeitos sócio-histórico-culturais (FREIRE, 2014, p. 12) que carregam estas marcas na sua subjetividade, no seu aprender a conhecer, no saber intervir e criar no seu cotidiano e no saber ser pedagógico.

A transdisciplinaridade é um território onde habita o caos e cuja ordem se encontra na articulação existencial interdisciplinar. Ela não é fixa, acabada com limites inacessíveis à intervenção criadora, mas rizomática, vivenciada enquanto dinamizadora da resolução dos problemas do recorte ao caos.

É na postura de problematização aberta (não retórica), na escuta dialógica, na convivência amorosa (FREIRE, 2014; BAKHTIN, 2011) e na aceitação dos processos criativos (comparar, valorar, intervir, escolher, decidir) dos seus alunos, que ocorre a aprendizagem. E, neste exercício ético e estéstico (de diálogo, de escuta, de aceitação) alunos e professeores vão se transformando, em função do tensionamento transgrediente do que são e da sua interpretação do mundo (seu contexto situacional, problema).

A abordagem transdisciplinar na escola não pretende ser uma "varinha mágica", que resolve todos os problemas inerentes à diversidade de situações de aprendizagem. É antes uma contribuição no sentido de utilização duma metodologia que permita ao aluno uma percepção e entendimento integral do assunto, reconhecendo os seus fragmentos. Uma prática transdisciplinar será mais eficaz se tiver como premissa um ensino-aprendizagem rizomático, não linear, sequencial (lógica de produção seriada). Isto obriga a uma articulação e comunicação constante entre as áreas disciplinar. Não se trata de dividir o problema avassalodor por partes para melhor aniquila-lo, mas de entendé-lo no seu fluxo existencial, dialogar com ele e com os paradigmas existemtentes (multi-inter-trans-disciplinaridade), o 
que não nos parece novo, no entanto, é inovador! A articulação entre as áreas disciplinares teria maior acolhimento nas séries iniciais $-1^{\mathrm{a}}$ à $5^{\mathrm{a}}$ Classe do Sistema Nacional de Educação em Moçambique - onde o aluno, na turma, interage com um único professor e, é mais desafiador em séries mais avançadas onde se tem vários professores atuando na mesma turma. Em todos os casos deve haver interesse dos professores em adoptar este o outro modo de fazer pedagógico, tendo em conta a sua adequação ao contexto situacional.

A criação e utilização ou a adoção de um modelo de formação (prática pedagógica) deve ser um processo informado, incorporado, vivenciado, e com a participação consciente e automática dos seus atores nos diversos níveis (gestores, professores, alunos, auxiliares). Quando um prática pedagógica é convicente, bem estruturada e tem aprovação dos gestores da instituição, tem fortes chances de ganhar força de lei.

\subsection{Dilemas éticos}

Segundo Gilles Deleuze (1996 apud AXT, 2008, p. 94), a ética é um conjunto de regras facultativas que fixam o valor do que fazemos, do que dizemos, segundo o modo de existência que isso implica. Modos de existência ou estilos de vida - cultura - estão sempre implicados nos gestos, na palavra, e constituem-se em valores axiológicos que nos produzem como este ou aquele.

Sobre a diferença entre a ética e a moral, está em que a moral se apresenta "como um conjunto de regras que coagem, regras de um tipo especial que consistem em julgar as ações e as intenções a partir de valores transcendentes (está bem, está mal...)" (GILLES DELEUZE, 1996 apud AXT, 2008, p. 94), isto é, enquanto a moral é dada a priori, é um preceito, a ética é construida e negociada na relação com o contexto, a ética é questionadora.

Bakhtin (2012) distingue a ética formal/teórica (material, universal, de Kant e dos kantianos) da ética prática, que se desenvolve da relação eu-outro e dos valores que sustentam e participam da composição dessas interações: escuta, acolhimento e até mesmo resistência como ato responsável.

Na sua responsabilidade, o ato coloca diante de si sua própria verdade como verdade que une ambos os seus aspectos, assim como une o aspecto do universal (a validade universal) e do individual (o real). Esta verdade unitária e singular do ato é posta como tarefa enquanto verdade sintética. (BAKHTIN, 2012, p. 81)

O conceito de ética em uso no presente estudo guarda relação à perspectiva do ato ético em Mikahil Bakhtin. O ato ético se "expressa como a relação do dever para com a realidade" (BAKHTIN, 2010, p. 32), um dever que não é de imposição, mas que me obriga - 
não no sentido universal de uma imposição e de cumprimento de uma formalidade que vem de for a de mim, mas no sentido do meu agir responsavelmente na base do meu não-álibi no existir-evento. Não-álibi significa "sem desculpas", "sem escapatórias", mas também “impossibilidade de estar em outro lugar” em relação ao lugar único e singular que ocupo no existir, existindo, vivendo (PONZIO, 2012, p. 20) - e me remete a uma atividade que exprime uma ação responsiva, que eu sozinho, "e nenhum outro no meu lugar, devo responsavelmente fazer, de maneira não formal" (BAKHTIN, 2012, p. 15).

Numa primeira aproximação e com base no Dicionário brasileiro de língua portuguesa, podemos considerar dilema como uma situação embaraçosa com duas saídas difíceis ou penosas. Se diante dessa situação o sujeito tenha que fazer uma escolha com base numa prática moral ou valores de convivência social nos quais ele acredita, está se diante do dilema ético. Dessa maneira, dilema ético seria uma situação problema, cuja solução se efetiva a partir de alternativas ou premissas contraditórias e mutuamente excludentes, partindo duma reflexão prévia sobre o comportamento e decisão, visando salvaguardar o respeito às relações humanas; porém, incluem-se também aquelas situações em que nenhuma solução é satisfatória do ponto de vista ético de respeito aos direitos humanos, ambientais e dos animais. Esta noção de dilema é válida em situações em que duas opções já estariam dadas de antemão.

Contudo, se considerarmos um cenário em que o aluno implicado é capaz de criar, inventar soluções, mesmo que provisórias, para sair eticamente da situação problema, não estaríamos vivenciando o desdobramento do dilema oferecendo mais que duas opções - ou isto ou aquilo; mas reverberando-o em múltiplas possibilidaddes de saída e que podemos nomear como "polilema ético"? Polilema ético pelo facto da saída ao problema, enunciada pelo aluno, estar relacionada ao ato ético de escuta e acolhimento de outras vozes - na perspetiva bakhtiniana, o termo "voz" refere-se à consciência falante que se faz presente nos enunciados. Tal consciência não é neutra, está sempre refletindo percepções de mundo, juízos e valores (SOUZA, 2011, p. 3) - "apontando para a diversidade, a multiplicidade, a complexidade" (AXT, 2011a, p. 47-48) dos posicionamentos ético-políticos dos alunos e do professor nesse ambiente de discussão dialógica. Nesse caso, o dilema vai além das escolhas bipolares, mais como linhas de fuga, fornecendo pontos de vista diversos sobre a situação, apontando para uma abertura e acolhimento da solução, mesmo que temporária, diante de um problema ou impasse concreto (real ou virtual/imaginário). Linhas de fuga são entendidas, na perspectiva deleuziana, como vetores de "desorganização" ou de "desterritorialização" que permitem um "corte" no caos e seu enfrentamento. Não se trata de fugir (abandonar, mudar de vida) e sim, de fazer fugir as certezas sobre o caos, deixando-se afectar pela vivência da 
situação, para se abrir a um novo horizonte além do dado não dado, no mesmo plano, o de imanência.

\subsection{Transdisciplinaridade no Forchat}

Forchat é um software que agrega funcionalidades de um Ambiente Virtual de Ensinoaprendizagem (AVA) - agregando as funções de fórum (regulamentado ou não), do chat (bate-papo) e portfólio (mural) - mas mais voltado à aprendizagem do que ao ensino. Segundo Mutti e Axt (2008), o ForChat é uma ferramenta de comunicação disponível on-line, que possibilita uma escrita autoral embasada nas interações dialógicas de caráter teórico conceitual-metodológico, estético-ficcional e real entre os seus participantes (alunos e professores de vários níveis de ensino). O ForChat foi criado para propiciar ações pedagógicas à distância que proponham uma intensiva interlocução virtual entre participantes dispostos a discutir um tema, um autor, um projeto ou, inclusive, escrever um ensaio em conjunto.

Esta ferramenta, gestada no Laboratório de Estudos em Linguagem Interação e Cognição (LELIC) da UFRGS, encontra-se disponível na web (http://www.ufrgs.br/lelic/index.php/projetos-de-pesquisa/forchat) para utilização em pesquisas se debruçando sobre o desenvolvimento de metodologias de interação na educação e em ambientes virtuais de aprendizagem.

O ForChat apresenta uma estrutura visada a impulsionar e potencializar os processos de produção autoral inter/transdisciplinar, envolvendo a emergência de novos sentidos, bem como a construção conceitual, continuamente realimentada a partir de novas contribuições, tornando visíveis novas e sutis diferenciações, novas e mais ricas composições. A interface da ferramenta Forchat é intuitiva e de fácil utilização, exigindo dos participantes a imersão no contexto da discussão. A leitura e produção de mensagens dão-se no mesmo espaço interativo, durante todo tempo. Esta imersão configura-se como ato ético de acolhimento de outros, pois exige que o sujeito fique junto com os demais, incluindo-se no círculo da conversação e interagindo com o que se produz nessas relações, como ingredientes do ato de criação.

O backbone, ao nível da programação, consiste de interfaces de criação que possibilitam o intercâmbio de informações em formato de lista de discussão, cujos registros são armazenados on-line em um banco de dados MySQL, ordenados por meio da programação em PHP, para posterior exibição em browser. Para utilizar o Forchat, os 
participantes devem ser previamente cadastrados nas salas. Cada participante deve possuir uma identificação, uma senha e um ícone-avatar (facultativo) que o representa.

As mensagens (conversas) são armazenadas por semana, associando a mensagem ao usuário, data e horário, garantindo fiabilidade das produções individuais e coletivas e permitindo a gestão facilitada dos usuários. $\mathrm{O}$ aluno tem a possibilidade de, pelo o link "Mensagens não respondidadas", escolher o período (semana) e identificar comentários e postagens nos quais colegas solicitam comentários/posicionamentos, ou apresentam conteúdos de seu interesse para aprofundamento. As conversas passadas permanecem disponíveis para interação numa estrutura que garante a continuidade do debate dos assuntos tratados.

Durante as atividades realizadas no ForChat, os alunos tiveram o privilégio de visualizar a construção do seu próprio percurso de discussão ao longo da disciplina e que serviu de base para a elaboração do relato reflexivo (memorial individual), tendo como pressuposto as interações dialógicas ou dialogismo bakhtiniano, ocorridas no chat-fórum e portfolio - espaços construção autoral coletiva. O dialogismo bakhtiniano pressupõe uma participação ativa no diálogo: interrogar, ouvir, responder, concordar, etc. Nesse diálogo o homem participa inteiro e com toda a vida: com os olhos, os lábios, as mãos, a alma, o espírito, todo o corpo, os atos” (BAKHTIN, 2011, p. 348). Para Fiorin (2006, p. 55), “o dialogismo é princípio de constituição do indivíduo e o seu princípio de ação”. O dialogismo é o princípio constitutivo do enunciado e da enunciação que considera todo o enunciado constituir-se a partir de outro enunciado. O dialogismo preconiza uma interação viva e tensa entre os enunciados, uma relação dialógica entre enunciador e receptor. Nessa interação há ao menos duas vozes (harmoniosas ou conflitantes) em diálogo - polifonia - vozes sociais e individuais.

Partido das leituras de textos seleccionados para a disciplina e outros sugeridos pelos pares (alunos participantes) no curso das discussões em ambiente presencial e no virtual, os alunos construiram a sua percepção sobre o papel da inter/transdisciplinaridade na perspectiva da complexidade e do paradigma ético-estético na prática pedagógica e como operadores metodológicos na pesquisa e na formação em Ciências Humanas/Educação. Uma vez que, todos podiam e deviam comentar diretamente os texto dos colegas, problematizando as suas contribuições, isso gerou dilemas éticos - os conteúdos da disciplina como disparadores desses dilemas e suscitando reflexões.

O espaço Forchat (sala 63) foi desenvolvido pela professora da disciplina "Inter/transdisciplinaridade, Complexidade e a perspectiva (Est)ética” (do Programa de Pós- 
Graduação em Informática na Educação do Centro Interdisciplinar de Novas Tecnologias na Educação da Universidade Federal do Rio Grande do Sul), que contou com a colaboração duma aluna para a gestão técnica (autorização dos acessos à sala, problemas com envio de ficheiros, esclarecimento de dúvidas), tendo sido justificada, a sua escolha, pelo referencial das suas vivências neste ambiente.

Todos os alunos participantes interagiram expressando argumentativamente as suas idéias, numa interlocução que, no final, não comprometeu a escrita autoral. Deste exercício resultaram memórias ricos em contribuições oriundas da participação colaborativa e diferenciada fortemente impregnada pela escuta e sem aceitação passiva, responsável, como nos propões Bakhtin (2011). Os dilemas éticos representam a dificuldade da humanidade em fazer escolhas quando duas opções são igualmete favoráveis (são igualmente boas e igualmente más), tendo em conta os seus valores morais e éticos.

A vida é feita de escolhas. A situação contreta (acontecimento) é que nos permite tomar uma decisão ou outra. Bakhtin nos convida a exercitar a responsabilidade nas nossas escolhas, através da escuta do outro emanente ao contexto. Nossas decisões e posicionamentos devem ter fundamento central a responsabilidade da relação com o outro, do ponto de vista axiológico (ética, moral) e deontológico (código e norma).

Do engajamento dos alunos na discussão das temáticas desenvolveram-se propostas de solução de problemas (dilemas éticos), ao mesmo tempo que novos problemas foram sendo criados e não sempre resolvidos, mas vivenciados, sentidos. A atmosfera gerada testemunhou uma mobilização do pensamento pela sensibilidade do problema inventado. Os conhecimentos de àreas disciplinar específicas foram usados para incorporar os movimentos de criação e vivenciamentos dos problemas - dilemas éticos. Estas constatações ajudam-nos a dicotomizar a relação ensino-aprendizagem. Até que ponto o aluno aprende o que o professor ensina? Quando efectivamente aprendemos?

A Pedagogia tradicional (do século XX) considera a unidade de ensino-aprendizagem, estabelecendo hierarquias e dependências entre o ensino e a aprendizagem, isto é, o sujeito só aprende quando outro sujeito o ensina, o sujeito só ensina quando aprende. As implicações menos abonatórias desta dicotomia consistem em considerar que o sujeito só aprende o que é ensinado, e do jeito que lhe é ensinado. A respeito dos videogames, Prensky (2010) refere o seguinte:

[...] eles se tornaram experiências profundas, ricas, que duram trinta, cinquenta ou mesmo cem horas e atraem meninos e meninas, adultos e jovens, mulheres mais velhas e, de fato, pessoas de todas as idades e grupos sociais. Mas eles prendem 
especialmente nossos filhos. [...] o verdadeiro segredo, que faz nossos filhos dedicarem tanto tempo aos games, é o conhecimento que adquirem! E esse aprendizado é importante para o tuturo de cada um deles. (PRENSKY, 2010, p. 29)

De certo, há sempre o sujeito que ensina, mas o que alguém aprende depende mais da sua disposição para aprender. Não sabemos qual mágica levou tal aluno a aprender tal conteúdo do jeito que aprendeu, nas condições em que aprendeu, tampouco ele nos pode revelar. "Ninguém aprende sozinho. Tampouco ninguém ensina ninguém. Os homens apredem em comunhão, mediatizados pelo mundo" (FREIRE, 2014). O sujeito aprende do encontro, da escuta e da interação com o problema, mobilizando o seu pensar.

A figura 1 mostra o nível de participação dos alunos nos discussões no Forchat, por semana, durante 13 semanas. O período de análise das discussões no Forchat, compreende a semana de 17/03/2014 à 25/05/2014. A semana de 10/03/2014 não registro atividade relevante devido a constrangimentos relacionados a: (1) Autorização dos acessos pelo administrador do sistema. (2) Alunos com dois cadastros, tendo usado mesma conta de email, a sua inscrição na sala virtual não foi validada, tendo sido postergada por mais dois dias. (3) Dificuldades de envio de arquivos (anexos). Ora todos este entraves foram ultrapassados e serviram para aprimorar as funcionalidades e a gestão das aprendizagens no ambiente virtual.

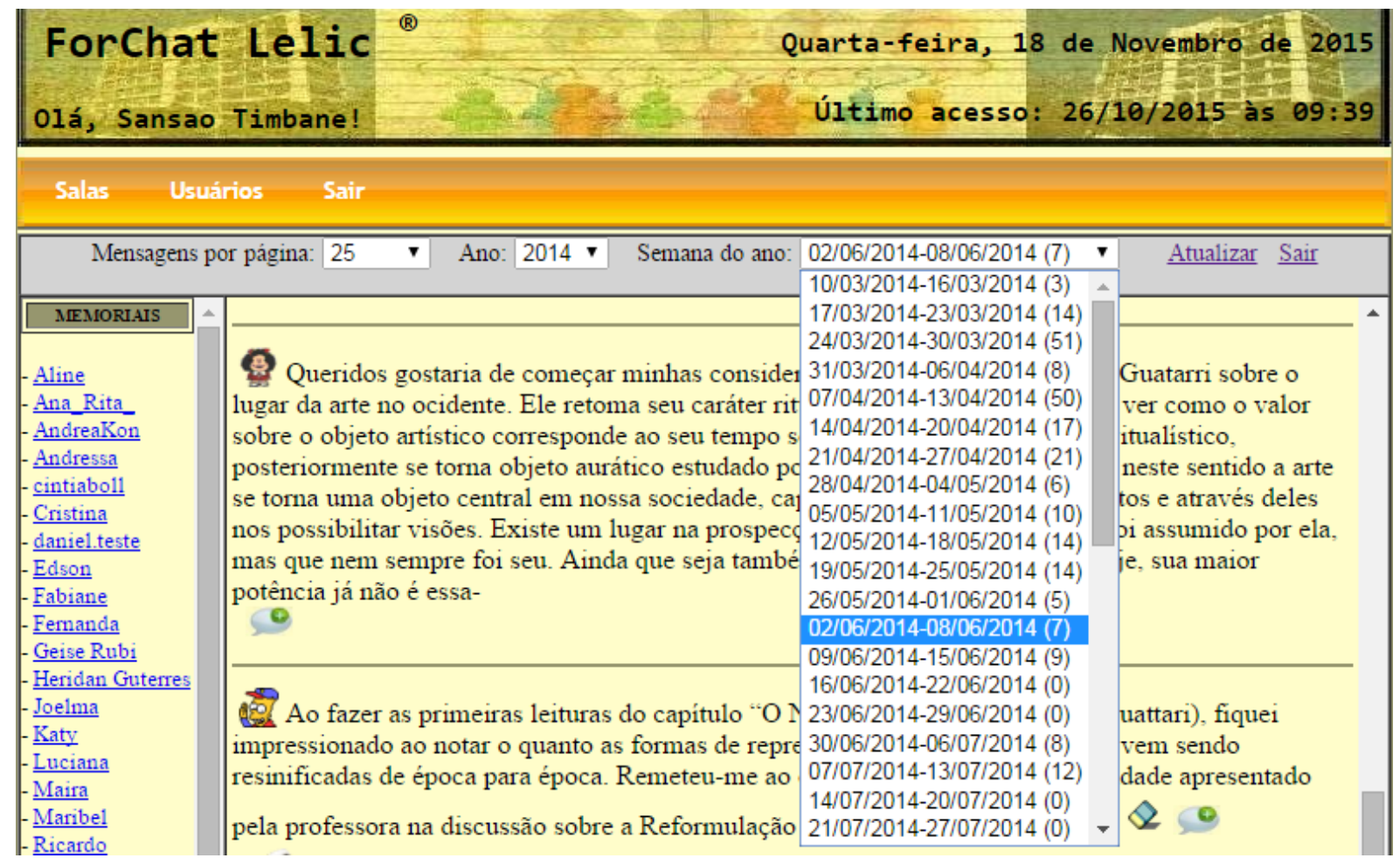

Figura 1- Participação dos alunos nos discussões no Forchat. Datas das aulas e número de postagens que foram realizadas por semana.

Fonte: Autor, disponívem em: http://lab.lelic.ufrgs.br/forchat/forchat_portal.php 
Ao participar das discussões dos textos propostos na disciplina e das suas contibuições em sala de aula presencial e no Forchat, os alunos testemunharam sua criatividade, autonomia, espírito investigativo e aprendizagem colaborativa. As contribuições dos colegas foram impactantes ao ponto de provocar mudanças no foco de pesquisa, havendo alunos que mudaram radicalmete os seus projetos de pesquisa. Neste sentido, o Forchat configurou-se como um espaço de interação e de análise parcial de desempenho dos alunos, da mesma maneira que se constituiu como um meio aberto à proliferação dos sentidos e ao encontro tensionado, e de resistência entre os sentidos, que possibilitou a produção de novos sentidos. Para Deleuze e Guattari (2000) e Axt (2005) apud Mutti e Axt (2008, p. 349), “o meio é 'o lugar onde as coisas adquirem velocidade'; em outras palavras, o meio é onde os sentidos proliferam, abrindo à multiplicidade de cruzamentos entre séries de sentidos, desfazendo os fechamentos".

\section{Resultados}

Os resultados encorajam a adoção duma proposta metodológica ancorada em dilemas éticos para abordar temas transversais em contexto multidisciplinar. Neste processo, houve evidências duma aprendizagem contextualizada e significativa, através do exercício responsável de participação efetiva e de contribuição para o coletivo, sustentado em uma escuta dialógica, enquanto condição para uma perspectiva ético-estética, de acolhimento e potencialização dos modos de pensar e agir do outro, na relação consigo e de sua própria expressividade.

Estes resultados de aprendizagem são também abonados por Bischoff (2015), num estudo embasado no Forchat e com o mesmos grupo de alunos, ao se debruçar sobre aos números significativamente altos dos enunciados postados pelos alunos no Forchat e a sua aprendizagem.

O Forchat (...) produziu 249 enunciados, sendo que durante duas semanas permaneceu inativo por problemas técnicos. Vinte e um estudantes participaram em algum momento no Forchat, por semana foram produzidas em média 15 mensagens e, por estudante, 11 mensagens. Evidente que esta quantificação não retrata o que de fato aconteceu quanto à quantidade das interações e aprendizagens que se produziram. Elas revelam a inserção dos membros, a participação dos mesmos, pois contribuíram com seus enunciados até o final da disciplina. (BISCHOFF, 2015, p. 137)

As discussões no Forchat (Ambiente Virtual de Aprendizagem) evidenciaram que é necessário uma planificação, uma sistematização preliminar, mas que esta não deve ser absoluta e escravizadora, permitindo focar não apenas no conteúdo, como também nas relações que se estabeleceram entre os sujeitos de aprendizagem, destes com o contexto. 
Trata-se da aprendizagem da vida em coletivo voltada para o saber se relacionar, uma ampliação do conceito de educação para a certificação-culminância, mas do aprender como acontecimento e do se encantar com a magia desse acontecimento.

\section{Considerações finais}

A utilização de dilemas éticos como proposta metodológica para abordar temas transversais, é um caso particular das metodologias participativas, comprometidas com o papel interventivo, participativo do aluno. A escola e a educação se enriquecem de significado, proporcionando convivíos animadores de encontro e produção de conhecimento, de resgate do coletivo e coexistência. O professor reconhecendo que o aluno tem uma palavra, tem algo a acrescentar. O professor e escuta, e ele se sentevalorizado e a sua autoestima se eleva.

Os problemas do cotidiano (e do aluno) são polifónicos do ponto de vista disciplinar, sua abordagem demanda um modo de pensar e interagir com eles diferente, que considere as partes no problema, mas sem perder de vista a complexidade da sua totalidade, sem perder a pureza desse híbrido. A inter/trasdisciplinaridade abrem para possibilidades de atender e entender os assuntos transversais/problemas da vida no nosso cotidiano, numa atmosfera caracterizada pela antecipação da informação e pela rápida contribuição das diferentes áreas de conhecimento proporcionados pelo advento das Novas Tecnologias de Informação e Comunicação.

Contudo, o legado da abordagem transversal das temáticas na atualidade não deve ser normalizador e, por consequência, reducionista, tal viés conduziria ao fechamento organizativo semelhante ao do arranjo disciplinar. No entanto, a contribuição da transversalidade centra-se numa visão integrada de equilíbrio no desconforto com o pensar e agir do outro, sendo a (est)ética da escuta dialógica o factor de aprendizagem no processo em si - trata-se de uma cultura de aproveitamento das possibilidades de aprendizagem que a coexistência desses modelos podem propiciar.

\section{Referências}

ALVARENGA, Augusta Thereza et al. Histórico, fundamentos filosóficos e teóricometodológicos da interdisciplinaridade. In JR, Arlindo Philippi; NETO, Antônio J. Silva (Org.). Interdisciplinaridade em Ciência, Tecnologia \& Inovação. São Paulo: Manole, 2011. p. 3-68.

AXT, Margarete. Do pressuposto dialógico na pesquisa: o lugar da multiplicidade na formação (docente) em rede. Informática na Educação: teoria \& prática, Porto Alegre, v. 11, n. 1, p. 91-104, jan./jun. 2008. 
AXT, Margarete. Mundo da Vida e Pesquisa em Educação: ressonâncias, implicações, replicações. In: Revista Letras de Hoje. Porto Alegre, V. 46, N 1, p. 46-54, jan./mar., 2011a.

AXT, Margarete. Inter/transdisciplinaridade, complexidade e a perspectiva (Est)ética. Porto Alegre: UFRGS, 2014. (Comunicação oral)

BAKHTIN, Mikhail. Estética de Criação Verbal. $6^{a}$ ed. São Paulo: Editora WMF Martins Fontes, 2011.

BAKHTIN, Mikhail. Para Uma Filosofia do Ato Responsável. 2a ed. São Paulo: Pedro \& João Editores, 2012 - Org. Augusto Ponzio; Grupo de Estudos dos Gêneros do Discurso. Tradução: Valdemir Miotello; Carlos Alberto Faraco.

BISCHOFF, Tânia Gomes. O aprender como acontecimento na EAD: análise de práticas e experiências. Porto Alegre: UFRGS, 2015. 157 f. Tese (Doutorado em Informática na Educação) - Programa de Pós-Graduação em Informática na Educação, Centro Interdisciplinar de Novas Tecnologias na Educação, Universidade Federal do Rio Grande do Sul, Porto Alegre, 2015. Disponível em: <http://hdl.handle.net/10183/128891>. Acesso em: 23 setembro 2015.

DELEUZE, Gilles; GUATTARI, Félix. O que é a Filosofia. $2^{\mathrm{a}}$ ed. $5^{\mathrm{a}}$ reimpressão Rio de Janeiro: Editora 34, 2007. Tradução Bento Prado Jr. e Alberto Alonso Muñoz

FREIRE, Paulo. Pedagogia da Autonomia: Saberes Necessários à Prática Educativa. $48^{\mathrm{a}}$ ed. Rio de Janeiro: Paz \& Terra, 2014.

LEIS, Héctor Ricardo. Especificidades e desafios da interdisciplinaridade nas ciências humanas. In JR, Arlindo Philippi; NETO, Antônio J. Silva (Org.). Interdisciplinaridade em Ciência, Tecnologia \& Inovação. São Paulo: Manole, 2011. p. 106-122.

MUTTI, Regina Maria Virini; AXT, Margarete. Para uma posição enunciativa no discurso pedagógico mediado por ambientes virtuais de aprendizagem. Revista: Interface -

Comunicação, Saúde, Educação. Porto Alegre. v.12, n.25, p.347-361, abr./jun. 2008.

Disponível em:

<http://www.ufrgs.br/lelic/files_gerenciador_de_arquivos/artigo/2008/56/1373314899artigo_ para_uma_posicao_enunciativa_no_discurso_pedagogico.pdf >. Acesso em: 25 junho 2014.

PARENTE, André. O Virtual e o Hipertextual: A rede como paradigma da conteporaneidade. Rio de Janeiro, 1999.

PENA-VEGA, Alfredo. Complexidade e Interdisciplinaridade: realidades e experiências de pesquisa. In JR, Arlindo Philippi; NETO, Antônio J. Silva (Org.). Interdisciplinaridade em Ciência, Tecnologia \& Inovação. São Paulo: Manole, 2011. p. 694-712.

PRENSKY, Marc. Não me atrapalhe, mãe - Estou aprendendo!: Como os videogames estão preparando os nossos filhos para o sucesso no século XXI - e como você pode ajudar!. São Paulo: Phorte editor, 2010. 
PONZIO, Augusto. A concepção bakhtiniana do ato como dar um passo. In: BAKHTIN, Mikhail. Para Uma Filosofia do Ato Responsável. $2^{a}$ ed. São Paulo: Pedro \& João Editores, 2012. p. 9-38.

SOUZA, Cristian Wagner de. Polifonia, Dialogismo e Gêneros: A presença de Bakhtin nas aulas de Língua Materna. 2011. Disponível em:

<http://www.unifia.edu.br/revista_eletronica/revistas/educacao_foco/artigos/ano2011/polifoni a.pdf> Acesso em: 20 setembro 2015. 